\title{
XXVIII. On oils gas
}

\section{Juste Preuss}

To cite this article: M. Juste Preuss (1825) XXVIII. On oils gas, Philosophical Magazine Series 1, 66:329, 203-206, DOI: $10.1080 / 14786442508673948$

To link to this article: http://dx.doi.org/10.1080/14786442508673948

曲 Published online: 10 Aug 2009.

Submit your article to this journal $\pi$

Џ Article views: 4

Q View related articles $₫$ 
made various trials, and the following process seems to me to be the best.

Pour some adhesive solution or tincture over the powder, and mix it with it into a stiff kind of liquid. Take with a brush or a stick a large drop of it, and apply it against the bottom of the cap.

This method is both quick and free from danger; whilst on filling with the dry detonating powder, the least careless touch may produce an explosion.

In order to prevent the corrosion of the cylinder, and its becoming useless by the formation of sulphuret of iron (an evil very common with iron touch-holes, and caused more by the action of the gun-powder than by that of the igniting substance), the inside of the cylinder should be lined with a metal which will neither oxidate, nor easily combine with the ingredients of the powder.

XXVIII. On Oil Gas*. By M. Juste Preuss, resident in Paris, formerly Inspector of Rivers and Forests of the Domaine Extraordinaire in Germany, and Member of several learned Societies.

THE prevalence of lighting with coal gas had gone on with 1 so much rapidity in England before Messrs. John and Philip Taylor of London had conceived the happy idea of making gas by means of oil, that after they had carried this branch of industry to a certain degree of perfection, the quarters of the metropolis and the provincial towns, where lighting with gas would have presented advantages, were already occupied by coal gas. The progress of the use of oil gas has necessarily been slow: it was first adopted in dwelling-houses and in gentlemen's seats, where they soon learned to esteem it on account of its salubrity and the beauty of its light, and because it does not change the gildings, plate, and stuffs, nor the paint nor pictures, as coal gas often does. Afterwards it was adopted in manufactories; still later in small towns and on high roads; and at present it is chosen in preference, even in the provinces which abound in coal pits, for the lighting of towns of the first order, to the great chagrin, and notwithstanding the opposition and clamours, of the coal

* Extracted from the Messager des Sciences et des Arts, Decembre 1824.

This scientific selection is published by the Royal Societies of the Fine Arts and of Agriculture at Ghent. It forms annually one volume of thirty sheets, in 8vo., embellished with several engravings, and is published in numbers, of from two to eight sheets, at Ghent, by P.F. De Goesin-Verhaeghe, No. 37, Hautport-street, at fifteen franes to subscribers. 
gas companies united, or, so to speak, leagued together, against this too dangerous competitor.

Oil gas possesses some characteristic properties which have procured it this preference which is given to it in England over coal gas. These properties not being generally known, I shall state some of the most remarkable. One single cubic foot of oil gas gives as much light as $3 \frac{1}{2}$ cubic feet of coal gas*. By this important fact the capacity of the gasometers (the most inconvenient part of the former system of lighting) is now reduced to less than a third part; the pipes to one third of their former capacity ; the size of the retorts, stoves, and apparatus for purifying and condensing, to one sixth; the cost of the apparatus generally, and the expense of keeping them up, to one third; lastly, the labour to less than the eighth part of that which it costs in a large establishment to feed with coal gas an equal number of burners of a given intensity. It will perhaps be objected to me, that the first material, the oil, on the one hand, is a dear and valuable commodity, whilst, on the other, coal is much less so in proportion. I grant it as regards certain countries; but I will add, that the daily expenses of a gas establishment are of two natures, either permanent, or susceptible of variation according as the sale of the gas diminishes or augments: the first are principally composed of the interest on the capital employed, of the rent of premises, and of the labour, as the labourers cannot be dismissed during the summer months, who have been instructed at an expense during the winter. Now these permanent expenses are inconsiderable in an oil gas work, and, comparatively, very great in a coal gas establishment. The second class of expenses includes the raw material, the consumption of which follows in exact proportion the sale of gas; and on this head gas works of each kind enjoy the same advantage. The winter season, which brings with it long evenings and revives balls, concerts, masonic meetings, \&c., augments and often increases tenfold the demand for light. A gas establishment ought to be prepared to meet those often unexpected calls, all of which decrease, and partly disappear with spring. Here then is what happens to the two kinds of lighting establishments, as Dr. Ricardo has judiciously observed before me : it is, that in the coal gas work the great expense remains the same, and the lesser expense diminishes; whilst in the manufactory of oil gas the lesser expense continues, and the great expense decreases, or even ceases, in equal proportion with the sale of light.

The inconvenient heat diffused by the combustion of coal

* Each being of the mean quality, that is to say, specific gravity : as for exanyle the coal gas 0.4069 , and the oil gas 0.9395 , the air being 1.0000 . 
gas in shops, \&c., is often complained of, and which, in effect, is proportioned to the number of cubic feet which are hourly burnt. It is almost superflorous to observe here that oil gas, for equal light, gives no more heat than Argand lamps. To all these adyantages, oil gas also unites that of being the only one which is suited for compression in portable lamps and in reservoirs, on account of its richness in light under a little volume.

As light only is wanted, we are not forced, as with coal gas, to create at the same time disagreeable residues, and accessory products, which would be gladly dispensed with; but on the more or less advantageous sale of which depends. nevertheless, the profit or loss of the undertaking; in short, in distilling oil, gas only is obtained.

The rise or fall of oils is moreover nearly indifferent to the manufacturer who knows how to produce good gas with raw oils of the most inferior qualities, such as will cost him, for example, forty-seven francs the hectolitre; whilst the consumer, to supply Ärgand lamps, must buy purified oil, perhaps at the rate of fifty-seven francs; besides that the light of an oil lamp is necessarily influenced by a number of circumstances more or less favourable: as by the length and uniform height of the wick; by the fmeness of the fibres of the cotton of which it is composed, and which help the capillary attraction; by its dryness, for it is a body sensibly hygrometric, and if it has become charged with humidity from the air, it is thereby less fit to imbibe the oil ; by its state of carbonization more or less advanced; by the actual level of the oil, always lowering (except in the beautiful lamp of Carcel); by the quality of the oil itself, and by the processes of purification it has undergone; lastly, by the more or less care with which the Argand lamp has been daily cleaned, \&c.; not to speak of the form of glasses and other circumstances which modify generally the effect of the various kinds of lights, without excepting gas.

Although these details may appear very trifling, they are notwithstanding, without exception, of such importance, that if there is a disproportion in one single point, the light of the Argand lamp must necessarily be imperfect; it is seen for this same reason how much this mode of lighting is subject to chance. I will say more : it is on the coincidence of all these nice points, with a just proportion of dry ambient air flowing in with a constant and regular speed, that the temperature depends at which the decomposition of the oil and the consequent combustion of the gas is 'effected. In short, if the temperature is too low, a portion of oil escapes, either under the form of oily vapour, or under that of smoke, without being burnt: if on 


\section{Drs. Christison and Turner on Oil and Coal Gas.}

the contrary the temperature is too high, the combustion is indeed complete and without smoke, but there is a partial destruction of light. ('This last point is the most delicate in the art of lighting, since the phænomenon is not directly perceptible by our senses.) In each case, a variable proportion of oil is expended in pure loss. Accordingly, I believe I do not exaggerate in stating, that Argand lamps which give the maximum of light due to the weight of oil they consume, are not less rare than capital prizes in the lottery.

Lighting with gas, on the contrary, is a process comparatively very simple, which dispenses with all care and attention; for the gas which freely escapes under a regular pressure through the orifices of a burner well executed and judiciously proportioned in its dimensions, cannot fail to give an invariable maximum of light.

It is by these considerations only that $I$ have been able to account to myself for a fact which appears very extraordinary at first sight; namely, that 100 pounds of raw oil converted into gas in a large apparatus, such as are constructed by Messrs. Taylor and Martineau of London for the lighting of towns, produce a quantity of light which cannot be produced by Argand lamps without burning at least 130 pounds, sometimes 150 pounds of purified oil ; and it happened to my friend the learned Professor M. Clement Desormes and myself; to make experiments in London on a quite new Paris Argand lamp, which consumed in the proportion of 318 pounds of oil for 100 pounds which its light only represented, in comparison with oil gas.

September, 1825.

XXIX. On the Comparative Advantages of Oil and Coal Gas. By Robert Christison, M.D. F.R.S.E., Professor of Medical Jurisprudence; and Edw. Turner, M.D. F.R.S.E. Lecturer on Chemistry, Edinburgh.*

THE paper (read before the Royal Society of Edinburgh, April 18, and May 2, 1825) from which the following extract is given, contains full details of a series of experiments undertaken at Edinburgh, as subordinate, in the first instance, to an inquiry regarding the illuminating power of oil and coal gases, at $n$ time when, from the projected establishment of an oil gas company, the question of the illuminating power of the gasès excited an extraordinary interest in that city; and the subject being taken up under the powerful influerice of private interest, a variety of statements were published by several scientific gentlemen as the result of their experiments, which, in-

* From the Edinburgh Philosophical Journal, vol, xiii. p. 34. 